\title{
EDIÇÃO DOS TEXTOS DE EULÁLIO MOTTA PUBLICADOS NOS JORNAIS O LIDADOR, O SERRINHENSE, VANGUARDA E GAZETA DO POVO
}

\author{
Iago Gusmão Santiago ${ }^{1}$; Patrício Nunes Barreiros²; \\ 1. Bolsista PIBIC/CNPq, Graduando em Letras com Espanhol, Universidade Estadual de Feira de Santana, e-mail: \\ gusmaoiago@gmail.com \\ 2. Orientador, Departamento de Letras e Artes, Universidade Estadual de Feira de Santana, e-mail: patricio@uefs.br
}

PALAVRAS-CHAVE: Eulálio Motta; jornais; edição.

\section{INTRODUÇÃO}

O projeto Edição das obras inéditas de Eulálio Motta visa à edição de sete obras inéditas do autor Eulálio de Miranda Motta (1907-1988), a partir das fontes preservadas em seu acervo pessoal. Segundo Barreiros $(2009 ; 2012 ; 2013)$, uma destas obras consiste em um projeto de publicação, no qual o escritor pretendia reunir todos os seus textos jornalísticos. Ele chegou a esboçar possíveis títulos e índices dos textos e escreveu para editores discutindo acerca dessa publicação.

Com base nisso, foi proposto o presente estudo que trata da edição semidiplomática dos textos publicados nos jornais $O$ Lidador, O Serrinhense, Gazeta do Povo, Mundo Novo e Vanguarda, nos quais o autor publicou diversos textos, chegando, inclusive, a possuir uma coluna em alguns destes periódicos. Vale ressaltar, que muitos desses textos também faziam parte de outros de seus projetos editoriais.

Mesmo se tratando de textos já publicados, deve-se levar em conta que estes são textos de difícil acesso para o público em geral, devido a sua localização e ao seu estado de conservação. Nesse contexto, a presente pesquisa se faz relevante pois possibilita o acesso a textos de grande valor cultural, responsáveis por guardar a memória de um povo e que antes estavam fadados ao esquecimento.

\section{METODOLOGIA}

Primeiro foi realizada uma edição semidiplomática dos textos, buscando manter a fidelidade ao texto original. Os textos tipográficos, diferente dos textos manuscritos, não apresentam rasuras, emendas ou qualquer outra interferência que poderia ter sido realizada posteriormente pelo autor, todavia existem informações que poderiam se perder se fosse realizada outro tipo de edição, como a ortografia utilizada na época, os erros tipográficos.

A edição segue a topografia do texto, transcrevendo de maneira linear. Está organizada face a face, com o fac-símile à esquerda e a transcrição à direita. Seguindo as recomendações da bibliografia sobre o assunto (Spina, 1994; Cambraia, 2005; Spaggiari \& Perugi, 2014) o método filológico da Crítica Textual será adaptado às necessidades especificas do texto. Considerando que os textos publicados em periódicos são versões ultimas de um texto e, portanto, não conterem interferências posteriores à sua publicação, não se fez necessária a utilização dos símbolos operadores da crítica genética, conforme os critérios apresentados por Barreiros (2012) para as demais obras de Eulálio Motta. Portanto, foram adotados os critérios adaptados para a edição dos jornais (Barreiros, 2015):

1. Indica-se a data do jornal, o número, a página e a coluna;

2. As linhas são numeradas de 5 em 5 à margem esquerda; 
3. Os textos são transcritos em fonte Times New Roman padrão Word; de tamanho 11, justificados à margem esquerda;

4. Transcreve-se o título como se encontra no original;

5. São mantidos a ortografia, a acentuação, o uso de maiúsculas e a pontuação.

6. Será utilizado o símbolo [†] para indicar trechos, palavras e letras ilegíveis;

7. As conjecturas serão indicadas por meio do símbolo ( );

8. Serão utilizadas notas de pé de página para indicar informações complementares tais como: alternância da cor da tinta, rasgões, furos, manchas, etc.

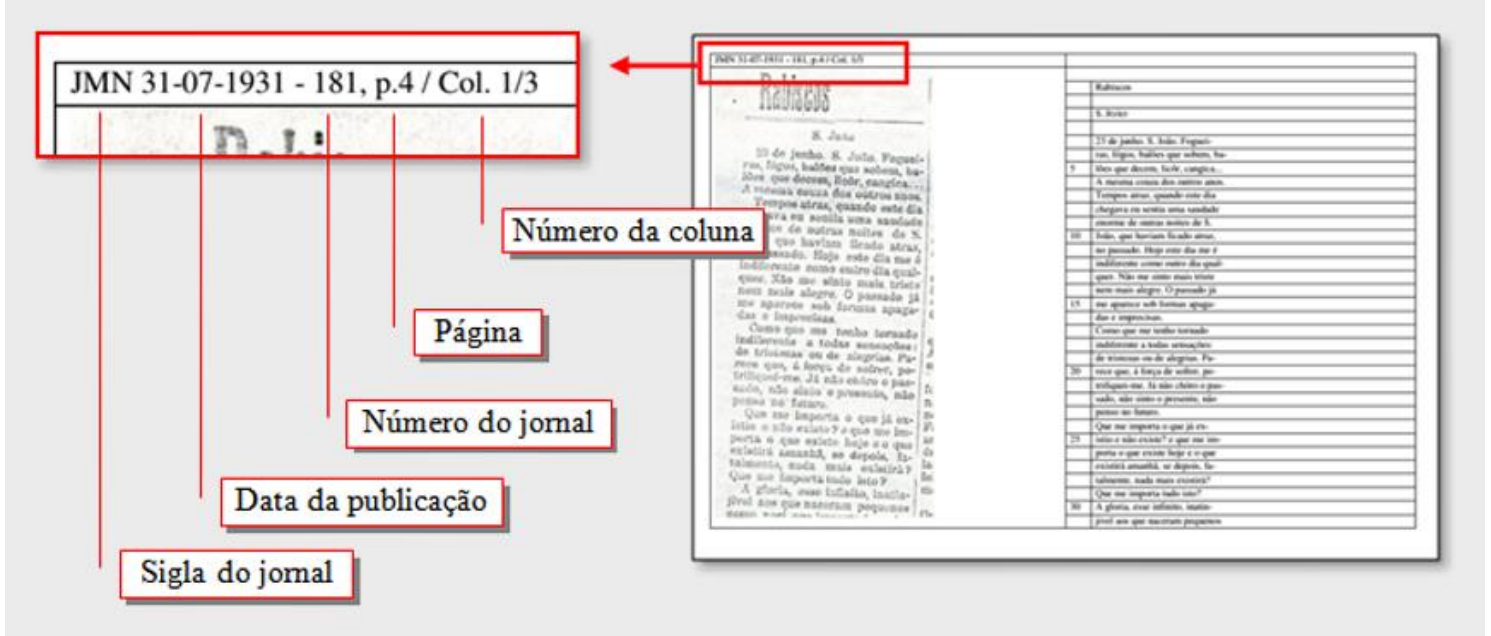

Figura 1: Exemplo de código catalográfico utilizado para identificar a edição realizada. Primeiro indica-se a sigla do jornal em que o texto foi publicado, seguida da data da publicação, do número do volume do jornal e, por fim, a página e a coluna em que a publicação se encontra.

\section{RESULTADOS E DISCUSSÃO}

O corpus é constituído por 139 textos de natureza diversa (crônicas, comentários sobre leituras, cartas, trechos de livros, poemas, etc.) publicados entre o ano de 1931 e 1961 . Os textos tratam de temas como opiniões sobre a política, a poesia da época, os fatos cotidianos, as festas populares, comentários sobre notícias diversas. A distribuição desses textos por periódico pode ser vista no gráfico abaixo:

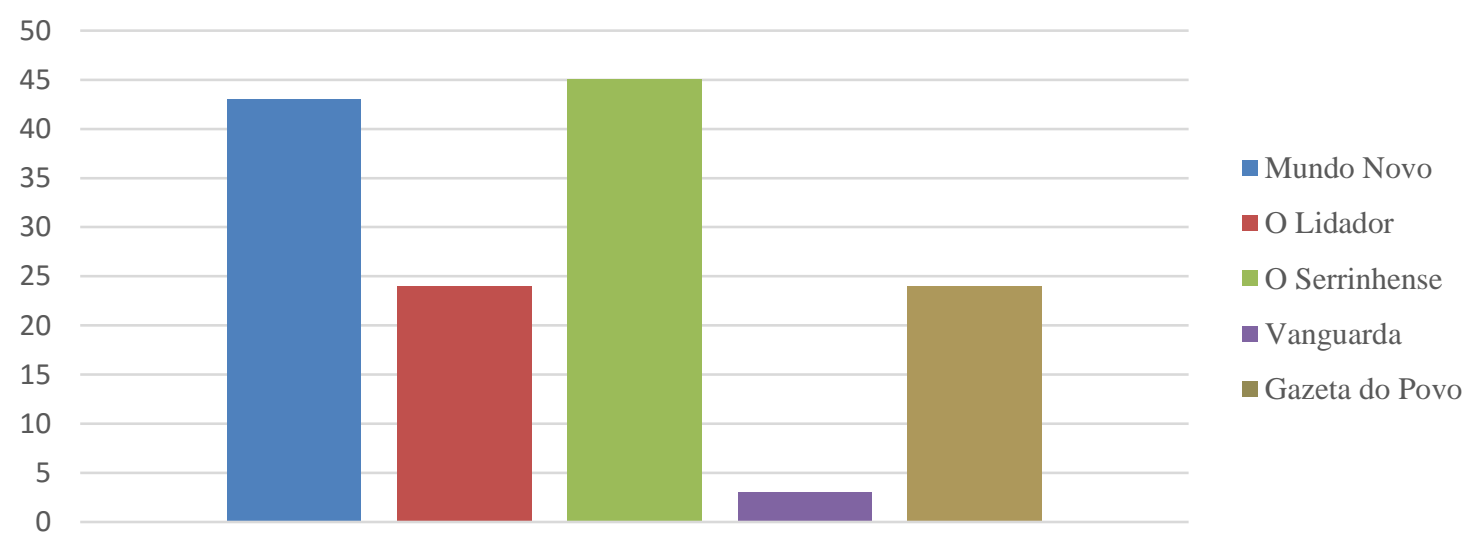

Figura 2: Quantidade de textos editados por jornal. Mundo Novo 23 textos; O Lidador 24 textos; O Serrinhense 45 textos; Vanguarda 3 textos; Gazeta do Povo 24 textos. 
Alguns dos textos, como os publicados no periódico $O$ Serrinhense, por exemplo, se encontram em excelente estado de conservação, ao contrário dos textos do jornal Mundo Novo e $O$ Lidador que são de difícil leitura. Em alguns dos periódicos existem textos que se encontram, em parte, ilegíveis, o que impossibilita a realização de uma edição completa como exemplificado na imagem a seguir:

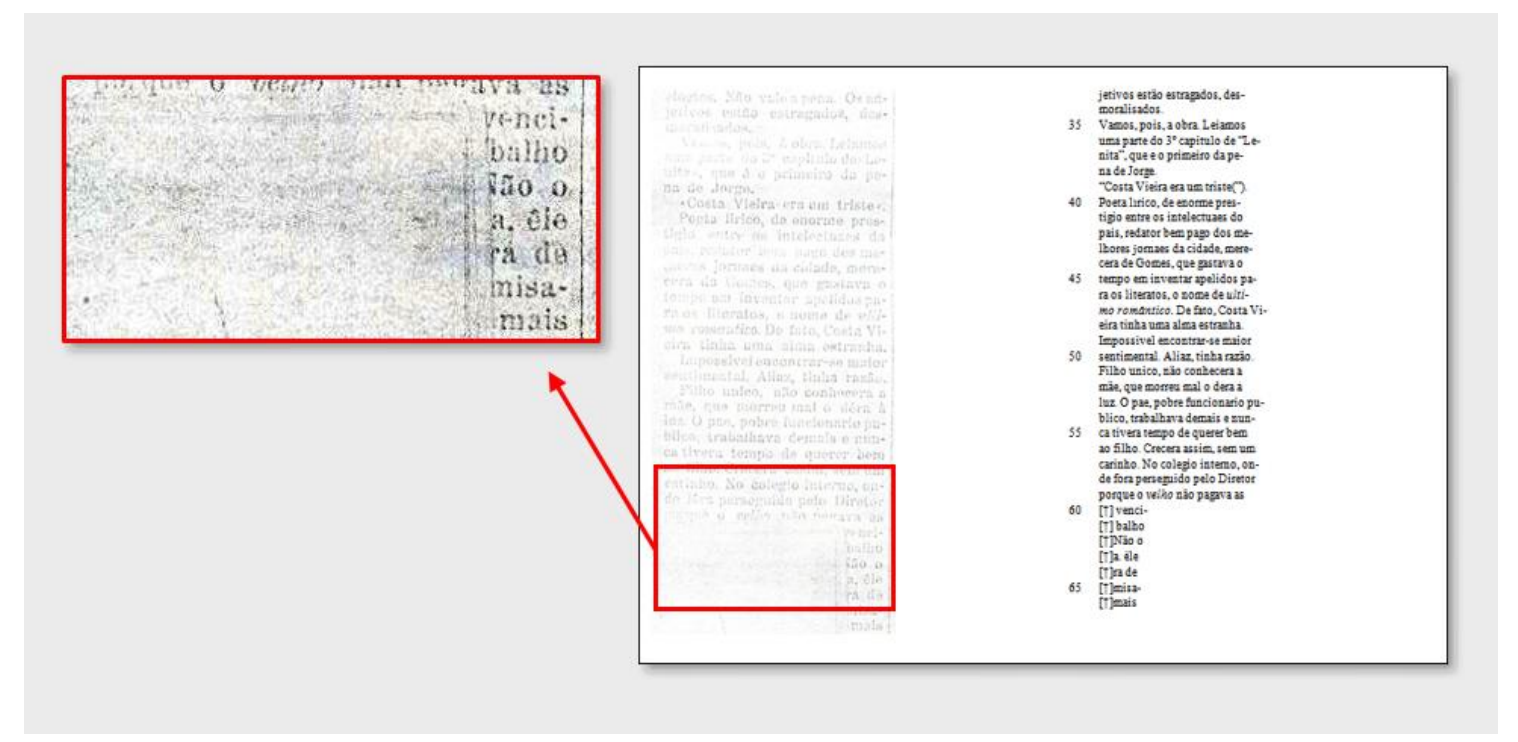

Figura 3: Exemplo de trecho ilegível encontrado no periódico Mundo Novo.

\section{CONSIDERAÇÕES FINAIS}

O plano foi cumprido de maneira exitosa com a edição de todos os fólios dos periódicos. A metodologia e os recursos de que o projeto dispõe, como a disponibilização de todos os fólios digitalizados, possibilitando a ampliação e manipulação destes facsímiles para que se possa lê-los com facilidade, bem como a acessibilidade dos arquivos do acervo, contribuíram para os resultados alcançados.

Os periódicos editados são fontes valiosas que nos permitem, a partir de sua edição e estudo dos textos, esboçar os itinerários do escritor Eulálio Motta enquanto jornalista, revelando sua postura em relação a assuntos diversos (opiniões sobre a poesia da época, a política nacional e internacional, os fatos cotidianos, as festas populares, leituras que fazia) e como se dava sua relação com os seus leitores. Além disso, esses textos trazem informações relevantes sobre a vida do autor, sua trajetória política e religiosa.

Os textos revelam, portanto, a relevância dos estudos desenvolvidos em acervos de escritores, os quais proporcionam um conhecimento mais aprofundado sobre a vida e a obra de seus proprietários. Nos levam também a compreender a necessidade existente de se editar periódicos antigos, os quais têm se mostrado preciosos testemunhos da história, das práticas culturais e da literatura, tanto baiana quanto nacional.

\section{REFERÊNCIAS}

BARREIROS, Patrício Nunes. Cantos tristes, no cemitério da ilusão: edição dos sonetos de Eulálio de Miranda Motta. 2007. 346 f. Dissertação (Mestrado em Literatura e Diversidade Cultural) - Departamento de Letras, Universidade Estadual de Feira de Santana, Feira de Santana. 
- Critérios de Edição dos Textos do Jornal Folha do Norte, 2015. Disponível em: $<\mathrm{https}$ ://eulaliomotta.wordpress.com/criterios-de-edicao-dos-textos-do-jornal-folha-donorte/>. Acesso em: 10 de set. de 2016.

Da organização do espólio à edição crítica da obra de Eulálio de Miranda Motta. In: CONGRESSO NACIONAL DE LINGUÍSTICA E FILOLOGIA, 9., 2005, v. IX, $\mathrm{n}^{\circ} 10$, Rio de Janeiro. Anais. Rio de Janeiro: UERJ, p. 117-128,2005.

O Pasquineiro da Roça, a hiperedição dos panfletos de Eulálio Motta. Feira de Santana: UEFS Editora, 2015.

CAMBRAIA, César Nardelli. Introdução à crítica textual. São Paulo: Martins Fontes, 2005.

MARQUES, Reinaldo. $O$ arquivamento do escritor. In: SOUZA, Eneida Maria de; MIRANDA, Wander Melo (Org.). Arquivosliterários. São Paulo: Ateliê Editorial, 2003. p. 141-156.

SPAGGIARI, Barbara; PERUGI, Maurizio. Fundamentos da crítica textual: história, metodologia, exercícios. Rio de Janeiro: Lucerna, 2004.

SPINA, Segismundo. Introdução à edótica: crítica textual. 2. ed. ver. e atual. São Paulo: ArsPoetica/EDUSP, 1994. 